\title{
Characteristics, Purification, and the Recent Applications of Soybean Oil in Fat-Based Food Products: A Review
}

\author{
Edy Subroto $^{1}$, Aldila Din Pangawikan ${ }^{2}$, Vira Putri Yarlina ${ }^{3}$, Nurisa Fadillah Isnaeni ${ }^{4}$ \\ Department of Food Industrial Technology, Faculty of Agro-Industrial Technology, UniversitasPadjadjaran, \\ Jl.Raya Bandung-Sumedang Km. 21, Jatinangor, Sumedang 40600, Indonesia. Email: ${ }^{1}$ edy.subroto@ unpad.ac.id, \\ 2 pangawikan@ unpad.ac.id, ${ }^{3}$ vira.putri.yarlina@ unpad.ac.id, ${ }^{4}$ nurisa17001@ mail.unpad.ac.id
}

\begin{abstract}
Soybean oil has a characteristic that is mainly determined by the content of polyunsaturated fatty acids in the form of high linoleic $( \pm 54,87 \%)$, so it is liquid at low temperatures and has a good effect on health. These make soybean oil much preferred to be applied to various food products. This review aims to provide information on soybean oil which includes physical and chemical characteristics, extraction and purification, as well as various current applications of soybean oil in different fat/oil-based food products. Soybean oil can be used for the production of oleogels/organogels, trans-free margarine and creamer, recombined butter, and mono-diacylglycerols. Soybean oil can rectify the physicochemical and nutritional properties of the products.
\end{abstract}

Key words: Soybean oil, fat-based food product, oleogels, trans-free margarine, recombined butter.

\section{INTRODUCTION}

Soybeans are the most dominant source of oil-producing grains produced in the world (around 60\%) due to the economic characteristics and quality of the oil favored by various industries [1]. Soybean has the main content of protein, reaching $40 \%$, but soybean also contains a high amount of oil, about 18-22\% [2], [3]. Soybean oil is generally extracted mechanically or using hexane solvent. Soybean oil contains unsaturated fatty acids around $85 \%$, where the polyunsaturated fatty acids (PUFAs), especially linolenic and linoleic acids are very suitable to meet the nutritional needs of essential fatty acids. However, soybean oil is relatively easy to undergo oxidation reactions. Therefore, soybean oil needs to be removed by impurities through the purification process and avoided from light and oxygen contact to prevent oxidation [4].

Soybean oil consists of triacylglycerol (90-95\%), but it also contains phosphatides, sterols, tocopherols, and other fat-soluble compounds. The amount of phosphatides in soybean is around $2 \%$ which consists of lecithin and cephalin.
The primary fatty acids in soybean oil are linoleate (54.87\%) and oleate (23.17\%) [5]. In general, soybean oil has several advantages compared to oils from other plants, including having a high PUFA content reaching 65\%, maintaining its liquid form at a lower temperature, can be selectively hydrogenated with semi-solid oil or other fats/oils, having a phosphatides content which can be isolated and have high nutritional value, and contain natural antioxidants in the form of tocopherol [6].

Soybean oil has been used in various foods, cosmetics, and pharmaceutical products. This review discusses the characteristics of soybean oil both the physical and chemical characteristics, extraction and purification processes, as well as the current applications of soybean oil, especially in the food industry. Soybean oil is often used as edible oil. However, soybean oil has now been used for a variety of processed fat/oil products, including being made into a mixture of margarine, recombined butter, oleogels, trans-free products, and can be modified into mono- and diacylglycerol or other structured lipids.

\section{PHYSICAL AND CHEMICAL CHARACTERISTICS OF SOYBEAN OIL}

\subsection{Physical Characteristics}

- Polymorph structure

The fat crystal structure is generally in the form of $\alpha, \beta$, and $\beta^{\prime}$. The type of $\beta^{\prime}$ has a small, needle-shaped crystal that creates the smoothest texture that is most preferred for shortening and margarine products. The composition of oil plays an important role in the formation of crystals. In general, soybean oil is dominated by $\beta$-shaped crystals, but modified soybean oil, such as hydrogenation, where crystals formed are dominated by $\beta$-shaped crystals [1].

\section{- Density}

Soybean oil has a density/mass that varies depending on the temperature; the lower its density at the higher the temperature. Sahasrabudhe et al. [7] reported that soybean oil has a density varying between $807.4-915.7 \mathrm{~kg} / \mathrm{m} 3$ in the temperature of $200-220{ }^{\circ} \mathrm{C}$. The density of soybean oil at room temperature is $915.7 \pm 0.7 \mathrm{~kg} / \mathrm{m} 3$. Meanwhile, according to Thomas [8], the density of soybean oil is 0.9220 - 
$0.9340 \mathrm{~g} / \mathrm{mL}$ at a temperature of $150 \mathrm{C}$.

\section{- Viscosity}

Viscosity is defined as resistance to flow from liquids or gases. The viscosity characteristics are produced from collisions between particles in the fluid that move at different speeds. The viscosity of soybean oil depends on the temperature; the viscosity is lower at the higher temperature. The viscosity of soybean oil varies from 57.1-2.8 mPa.s in the temperature range of $22-200{ }^{\circ} \mathrm{C}$. Soybean oil has a viscosity of $57.1 \mathrm{mPa} . \mathrm{s}$ and is liquid at room temperature [7]. According to Shahidi [9], soybean oil has a viscosity of 59-62 $\mathrm{mPa}$.s at $20{ }^{\circ} \mathrm{C}$. According to Wang [1], the viscosity of soybean oil is $50.09 \mathrm{mPa}$.s at $25^{\circ} \mathrm{C}$.

\section{- Specific Heat of Soybean Oil}

The specific heat of fats and oils determines the characteristics of the oil when heated, thus affecting the process conditions and their applications. The specific heat of oil depends on temperature. Specific heat is higher when at higher temperatures. Soybean oil has a specific heat ranging from 2,269-2,812 J/g.K at temperatures of $40-180{ }^{\circ} \mathrm{C}$ [10]. Meanwhile, according to Wang [1], the specific heat of soybean oil is around $0.458 \mathrm{cal} / \mathrm{g}$ at a temperature of $19.7^{\circ} \mathrm{C}$.

\section{- $\quad$ Melting Point}

Soybean oil has a relatively low melting point at about 0.6 ${ }^{\circ} \mathrm{C}$. The melting point of deodorized soybean oil is at a lower temperature, which is $-5.80{ }^{\circ} \mathrm{C}$, while the melting point of hydrogenated soybean oil is $36.8^{\circ} \mathrm{C}$ [11]. Fat with a melting point lower than $37^{\circ} \mathrm{C}$ can be used as shortening since it can melt as a whole in the mouth and does not give a waxy sensation when consumed [12]. Trans- fatty acids have a higher melting point than cis-, so the presence of trans- fats are preferred to create solid products, but trans- fat content can present a risk of coronary heart disease and atherosclerosis. According to Ribeiro et al. [5], soybean oil that modified through interesterification with fully hydrogenated soybean oil at a ratio of 70:30, has a melting point of $39{ }^{\circ} \mathrm{C}$, so that it is included in semi-solid or all-purpose shortening fat products, which is usually used for confectionery and bakery products.

\section{- $\quad$ Smoke Point, Flash Point, Fire Point}

The smoke point exhibited the temperature at which fat or oil begins to produce visible bluish smoke. Smoke point depends on free fatty acids (FFA) contained in fats/oils. The more FFA content, the oil/fat will smoke faster. Flash point exhibited the temperature at which oil water vapor can ignite when exposed to a source of fire (spark) in a short time, and then the fire will go out again. The fire point is the lowest temperature point where the oil/fat vapor will ignite when exposed to a fire source and will last for at least 5 seconds. Soybean oil has a fire point, flash point, and smoke point of 285, 270, and $250{ }^{\circ} \mathrm{C}$, respectively [13]. Meanwhile, according to Wang [1], the fire point, flash point, and smoke point of soybean oil are 363,328 , and $234^{\circ} \mathrm{C}$, respectively.

- $\quad$ Solid Fat Content (SFC)
SFC provides characteristics that are useful in developing and formulating a fat/oil product. SFC is responsible for spreadability, oiling-out, ease of packaging, appearance, and organoleptic characteristics of fat products. SFC gets lower when it is at higher temperatures. According to Hayati et al. [14], soybean oil has an SFC of about $0.16 \%$ at $5{ }^{\circ} \mathrm{C}$, and SFC has not been detected at temperatures above $10{ }^{\circ} \mathrm{C}$. Soybean oil is almost all in liquid form at $5-20^{\circ} \mathrm{C}$. Therefore, soybean oil is generally modified if used as raw material for making margarine or shortening.

\subsection{Chemical Characteristics}

\section{- Fatty acid composition}

The main fatty acids in soybean oil are linoleate (54.87\%), oleate $(23.17 \%)$, and palmitate $(11.50 \%)$, while the total unsaturated fatty acids in soybean oil are $84.2 \%$ [5]. The content of linoleic acid in soybean oil is highest among other sources of unsaturated fatty acids such as corn oil, cottonseed oil, and peanut oil. These fatty acids are very effective in preventing atherosclerosis and hypercholesterolemia [15]. Hayati et al. [14] also reported that the main fatty acids of soybean oil from the largest to the smallest were linoleate, oleate, palmitate, and linolenate. In general, soybean oil containing PUFA reaches $65 \%$. The high content is obtained from triacylglycerolsand is not fully saturated (the three fatty acids are not saturated). The high unsaturated fatty acid content in natural soybean oil makes triacylglycerol molecules (TAG) contain at least two or three unsaturated fatty acids, whereas di- and tri-saturated are generally very rare.

PUFAs contained in soybean oil can be degraded if exposed to heat. PUFA content will decrease due to oxidation reactions during frying and the formation of more polar compounds [16]. Soybean oil used for frying milanesas has decreased PUFA and increased MUFA. PUFA decreased from $60 \%$ to $56.4 \%$. These were mainly dominated by a decrease in linolenic acid, which dropped from 53.4\% to $50.3 \%$ [17].

Soybean oil is used by some industries in the form of hydrogenated soybean oil. Hydrogenation removes most of the double bonds, and most of the remaining bonds are isomerized into cis- or trans- fatty acids. The hydrogenation can increase the melting point, increase consistency when used for margarine, and reduce the oxidation potential. Karabulut et al. [18], analyzed changes in the composition of fatty acids and trans-fatty acids in soybean oil after hydrogenation and determined their effect on solid fat content. The decrease occurred because of saturation of the double bonds. The concentrations of trans- 18:1, and trans- 18:2 increased, while cis- 18:2 and cis- 18:3 fatty acids decreased. Cis- 18:2 fatty acids and cis- 18:3 decreased degree of unsaturation and turned into dienes and monoen from their isomers. Trans fatty acids (TFA) increased from only $2.06 \%$ to $56.76 \%$; total saturated fatty acid (TSFA) increased from $17.7 \%$ to $22.3 \%$; while the total unsaturated fatty acid (TUFA) decreased from $82.3 \%$ to $77.7 \%$. 


\section{- Triacylglycerol (TAG) composition}

The characteristics of fatty foods are very dependent on the composition of the triacylglycerol fats/oils used [19]. S3 triacylglycerol (melting point 54-65 ${ }^{\circ} \mathrm{C}$ ) and $\mathrm{S} 2 \mathrm{U}$ triacylglycerol (melting point $27-42{ }^{\circ} \mathrm{C}$ ) play a role in the structure of food products that contain these fats/oils. U2S triacylglycerol plays an important role in the mouthfeel characteristics of the product. At the same time, U3 triacylglycerol (melting point $-14-1{ }^{\circ} \mathrm{C}$ ) affects the softness of the product. Therefore, the increase in certain triacylglycerol in soybean oil obtained from chemical interesterification is often used to improve its functionality and sensory properties of the product [5].

The sn-2 position of the triacylglycerol backbone of soybean oil is dominated by linoleic acid, which reaches $66.3 \%$, followed by oleic acid around $22.7 \%$ and linolenic acid of $7.1 \%$ [1]. This shows that soybean oil has good nutritional properties because PUFAs such as linoleic and linolenic are superior when they are in sn-2 of the glycerol backbone. PUFA on sn-2 will be metabolized by the body to re-synthesis the vital tissues such as the heart, kidney, and brain [20].

\section{- $\quad$ Iodine number}

The iodine number in fat/oil shows the level of unsaturation of oil/fat. A higher iodine number exhibits a higher degree of unsaturation. According to Thomas [8], soybean oil has an iodine number of 120-136 g/100 g. Meanwhile, according to Oladiji et al. [13], soybean oil has an iodine number of $131 \mathrm{mg} / \mathrm{g}$. The difference can be due to differences in the type of soybean used and the different extraction methods.

\section{- $\quad$ Peroxide value $(P V)$}

$\mathrm{PV}$ is one way to measure how much oil/fat has oxidized or as an indicator of fat/oil stability against oxidation [21]. The higher the PV exhibits that fat/oil has oxidized or is more easily oxidized. According to Oladiji et al. [13], Soybean oil has a peroxide rate of around $7.60 \mathrm{mEq} / \mathrm{kg}$.

\section{EXTRACTION AND PURIFICATION OF SOYBEAN OIL}

In general, soybean oil extraction can be conducted by solvent extraction and mechanical pressing. Solvent extraction using hexane has become a standard often conducted in modern oil processing [1]. Solvent extraction uses the principle of oil solubility in non-polar organic solvents to extract oil from soybean flakes. The process of extracting soybean oil by a solvent is a diffusion process which is achieved by inserting a solid portion into the solvent [1]. When compared to mechanical methods, solvent extraction can eliminate about $0.5 \%$ oil residue by using less energy. Three steps that are often conducted in the solvent extraction of soybean oil, namely preparation of soybean seeds, oil extraction, and oil separation.
The solvent which is often used to extract soybean oil is hexane. However, today the use of hexane for oil extraction is debated because of its effect on the environment. Hexane in soybean oil extraction is wasted in large quantities, so it is feared that it can pollute the environment. Generally, every 1 ton of soybeans extracted will produce $1 \mathrm{~kg}$ of hexane waste [22].

According to the study of Phan et al. [22] concerning the extraction and separation of soybean oil using switchable solvents, replacing hexane for soybean oil extraction can be conducted using normal solvents (non-switchable) with moderate polarity, then taking the solvent back from oil by washing with water. The solvent in the water is then separated by dissolving $\mathrm{CO} 2$ into the mixture to induce phase separation. Once separated, the solvent can be reused so that no waste solvent can harm the environment. The requirement for this method to succeed is that the solvent must dissolve with soybean oil, can be extracted from oil using water, and can be separated from water using $\mathrm{CO} 2$ pressure. According to the results of experiments on three potential solvents (THF, dioxane, and acetone), the most suitable solvent for this method is dioxane.

Extracted soybean oil contains minor components such as phospholipids, oxidation products, chlorophyll pigments, and non-soapy components such as sterols, tocopherols, and hydrocarbons. These components can have a negative effect, while some others have a positive effect on nutrition and oil function. The purpose of purifying soybean oil is to eliminate unwanted components but can maintain components that provide benefits [1]. The purification process generally consists of degumming, deodorization, bleaching, and neutralization.

Degumming aims to remove gums and phospholipids in crude soybean oil to increase its stability. Soybean oil extracted by solvents contains phospholipids that can be hydrated around 90\%, while others cannot be hydrated. The total phospholipid in crude soybean oil is about 1.1-3.2\%. The amount of phospholipids depends on the extraction method used, especially in the preparation stage before the extraction process. Good soybean oil must contain phosphorus of less than 50 ppm [1].

Crude soybean oil contains free fatty acids (FFAs) that can be removed through the process of neutralization. Neutralization is basedon purification or de-acidification. Soybean oil is given an alkaline solution to neutralize FFAs in continuous or batch systems. Soap formed can also adsorb pigments, residual gums that are not hydrated, and several other polar compounds. The resulting soap can then be separated by centrifugation [1].

Pigments that are still present in crude soybean oil can be removed through the bleaching process. Bleaching clay that activated by acid is the most effective material for absorbing chlorophyll pigments and decomposing peroxide. Bleaching can also destroy peroxides to carbonyl compounds which have smaller molecular weights so that they can be removed during the deodorization process. Deodorization is an evaporation process where hot steam is injected into soybean 
Edy Subroto et al., International Journal of Emerging Trends in Engineering Research, 8(7), July 2020, 3003 - 3011

oil at $252-266{ }^{\circ} \mathrm{C}$ and vacuum pressure $(<6 \mathrm{mmHg})$. These conditions make the peroxide decompose, and free fatty acids and volatile compounds (odor) evaporated. Generally, purified/refined soybean oil through the stages of degumming, neutralization, bleaching, and deodorizing produce soybean oil with a phosphorus content of $1 \mathrm{ppm}$, iron $(0.3 \mathrm{ppm})$, and free fatty acids about $0.02 \%$ [1].

\section{THE APPLICATIONS OF SOYBEAN OIL IN FOOD PRODUCTS}

Refined soybean oil can be used to a variety of food products, such as for salad oil, cooking oil, as well as for various lipid modification processes. Modified soybean oil can be used for the production of oleogels, margarine, and other fatty food products. Various modifications and the use of soybean oil in food products can be seen in Table 1 .

Table 1: Various Applications of Soybean Oil in Food products

\begin{tabular}{|c|c|c|}
\hline Products & Characteristics of product & $\begin{array}{l}\text { Referen } \\
\text { ces }\end{array}$ \\
\hline \multirow[t]{4}{*}{ Oleogel } & $\begin{array}{ll}\text { - } & \text { G value }>\mathrm{G} \text { value at } 75^{\circ} \mathrm{C} \\
\text { - } & \text { Oleogel reduces oil absorption } \\
\text { by } 16 \% \\
\text { - } \\
\text { Oleogel peroxide number }<\text { pure } \\
\text { soybean oil }\end{array}$ & [23] \\
\hline & $\begin{array}{ll}\text { - } & \text { PUFA in oleogel> commercial } \\
\text { confectionery filling fat }(\mathrm{CFF}) \text {. } \\
\text { - } & \text { SAFA in oleogel< CFF. } \\
\text { - } & \text { Low SFC }(2.5-8 \%) \text { at } 0-30{ }^{\circ} \mathrm{C} . \\
\text { - } & \text { Oleogel melts completely at } \\
& 40^{\circ} \mathrm{C} \text {. } \\
\text { - } & \text { The oil migration of oleogel is } \\
\text { slower than CFF. }\end{array}$ & [24] \\
\hline & $\begin{array}{l}\text { - Oleogels do not affect the } \\
\text { sensorial characteristics of } \\
\text { bologna sausage } \\
\text { - The lipid globule in oleogels is } \\
\text { smaller than pork fat }\end{array}$ & [25] \\
\hline & $\begin{array}{l}\text { Organogels have the ability to } \\
\text { form stability crystalline } \\
\text { networks }\end{array}$ & [26] \\
\hline $\begin{array}{l}\text { Trans-free } \\
\text { Creamer }\end{array}$ & $\begin{array}{l}\text { - Interesterified oils do not have } \\
\text { trans fatty acids. } \\
\text { - There is no significant } \\
\text { difference in physical } \\
\text { properties with commercial } \\
\text { products. } \\
\text { - Non-dairy cream from } \\
\text { Interesterified oils can replace } \\
\text { commercial creamer. }\end{array}$ & [27] \\
\hline Margarine & $\begin{array}{l}\text { USFA margarine is } 3.2 \% \\
\text { greater than beef tallow (BT). } \\
\text { - The rate of crystallization of } \\
\text { margarine is } 18 \% \text { slower than } \\
\text { BT. } \\
\text { - Perfect melting margarine } \\
\text { (SFC = 0) at lower }\end{array}$ & [28] \\
\hline
\end{tabular}

\begin{tabular}{|c|c|c|}
\hline & $\begin{array}{l}\text { temperatures than BT. } \\
\text { - Margarine spreadability is } \\
4.5 \% \text { higher than BT. }\end{array}$ & \\
\hline & $\begin{array}{l}\text { Structured margarin fat has } \\
\text { suitable } \beta^{\prime} \text { polymorph, physical } \\
\text { properties, and desirable fatty } \\
\text { acid profile for margarine }\end{array}$ & [29] \\
\hline \multirow[t]{2}{*}{$\begin{array}{l}\text { Recombin } \\
\text { ed butter }\end{array}$} & $\begin{array}{l}\text { - Recombined butter is obtained } \\
\text { by interesterification of } \\
\text { MF:SBO at a ratio of 2:1. } \\
\text { - The spreadability of } \\
\text { recombined butter is higher } \\
\text { than pure butterfat and milkfat. } \\
\text { - The consistency of recombined } \\
\text { butter is } 66 \% \text { lower than butter } \\
\& 79 \% \text { lower than milk fat. } \\
\text { - The hardness of recombined } \\
\text { butter is } 32 \% \text { lower than butter } \\
\text { and lower } 86 \% \text { than milk fat. }\end{array}$ & [30] \\
\hline & $\begin{array}{l}\text { FHSBO (fully hydrogenated } \\
\text { soybean) has compatibility to } \\
\text { milk fat } \\
\text { - } \text { FHSBO raised the thermal } \\
\text { resistance of the blends } \\
\text { - FHSBO improve the } \\
\text { polymorphic habit of blends }\end{array}$ & [31] \\
\hline \multirow[t]{2}{*}{$\begin{array}{l}\text { Mono- and } \\
\text { diacylglyc } \\
\text { erols }\end{array}$} & $\begin{array}{l}\text { - Unsaturated fatty acids of } \\
\text { DAG-enriched soybean oils > } \\
\text { MAG. } \\
\text { - Iodin number of } \\
\text { DAG-enriched soybean oils > } \\
\text { MAG. }\end{array}$ & [32] \\
\hline & $\begin{array}{l}\text { - DAG-enriched soybean oil can } \\
\text { reduce serum triglycerides and } \\
\text { act as an anti-obesity }\end{array}$ & [33] \\
\hline
\end{tabular}

\subsection{Oleogels}

Oleogels are a two-phase colloidal system where liquid oil is immobilized by gelators that three-dimensional network of [34]. Oleogels are the bi-continuous micro-heterogeneous colloid system of solid and liquid phases. Oil is trapped in three-dimensional gel networks that provide solid-like characteristics without changing its chemical components [23]. Oleogels play a role as the substitute for solid fat which is expected to reduce the use of saturated fats in the fat-based food industry.

Lim et al. [23] conducted research on oleogel using ingredients consisting of soybean oil, palm oil, and Carnauba wax for frying of instant noodles. Oleogel properties are compared with soybean oil and palm oil, which includes viscosity, rheology, oil absorption, and peroxide rate. Oleogel viscosity is higher compared to soybean oil and palm oil at temperatures less than $80{ }^{\circ} \mathrm{C}$. Oleogel viscosity is more dependent on temperature than soybean oil. The value of $\mathrm{G}^{\prime}$ in oleogel is greater than the value of $\mathrm{G}^{\prime}$ at $75^{\circ} \mathrm{C}$. This indicates that the oleogel is solid at that temperature. The use of oleogel can reduce oil absorption by $16 \%$ without giving a negative effect on the texture of the noodles. Noodle samples given 
with soybean oil treatment have the highest peroxide number, which means soybean oil is most easily oxidized, while those treated with oleogel have lower peroxide numbers so that it is more stable to oxidation. Peroxide number is one indicator to measure the stability of oil against oxidation [21].

Si et al. [24] succeeded in making oleogel from soybean oil and evaluating oil migration with the praline system model. This study compared oleogel soybean oil-glycerol monostearate (MAG), soybean oil-lecithin-sorbitan stearate (Lec-STS), and commercial filling fat (CFF). The composition of fatty acids in oleogel and commercial filling fat (CFF) shows that oleogel has higher unsaturated fatty acids than CFF. Oleogel at low temperatures has a solid form and has a low solid fat content (SFC) that varies between $2.5-8 \%$ at $0-30{ }^{\circ} \mathrm{C}$, and oleogel melts completely at $40{ }^{\circ} \mathrm{C}$. SFC value is related to the melting point. OleogelLec-STS has a melting point below $40{ }^{\circ} \mathrm{C}$ which indicates that the oleogel melts completely at body temperature. The rheological analysis shows that oleogel has the same rheological characteristics as CFF. This shows that oleogel can prevent the migration of filling fats to the fat coating on the praline system and flows well when pumped through pipes in the processing process. Oil migration during storage shows that oleogel has slower oil migration than CFF [24]. In another study, Tarté et al. [25] reported that oleogel from soybean oil and rice bran wax could be applied to bologna sausage to replace pork fat. Bologna sausage which used oleogel has the sensorial properties that were not significantly different and produce smaller globular lipids than pork fat.

\subsection{Trans-Free Product}

Most natural oils and fats cannot be applied widely because of the specific structure of fatty acids and triacylglycerols [35]. Some technologies can modify the fat/oil either chemically (hydrogenation), enzymatic (interesterification), or physically (fractionation) [36]. Modification through hydrogenation has the potential to produce trans-fatty acids, which cause the risk of coronary artery disease. Biotechnological modification can be an effective method to improve characteristics and produce healthy products [20], [37], [38]. Therefore the method of interesterification, especially enzymatically, can be used as an alternative to getting the appropriate physical characteristics (plastic fats) without producing isomer of trans- fatty acids.

In interesterification, the composition of fatty acids is not changed but is redistributed into the triacylglycerol molecule backbone. According to Ribeiro et al. (Ribeiro et al., 2009), the intersection of soybean oil (SO) with FHSBO (SO: FHSBO) suitable for liquid shortening (90:10), margarine (80:20), confectionery/bakery (70:30), and for all-purpose shortening (60:40). Wang \& Liu [27] conducted a study on trans free non-dairy creamer made from soybean oil and FSHBO at a ratio of 40:60 resulting in SFC of less than 15\% at $38{ }^{\circ} \mathrm{C}$ to produce preferred mouthfeel properties. Interesterified oil does not have trans-fatty acids, while commercial creamer contains high trans fatty acids around $31.42-43.53 \%$. Non-dairy cream from enzymatic interesterification can be used to replace commercial creamer so that consumption of trans- fatty acids can be reduced. The interesterification product was then microencapsulated to form a powder. The resulting oil powder had a dry form with a moisture content of less than $6 \%$ and was white. Particle diameter varies from 5-25 um, and the distribution of particles was uniform so that encapsulated oil produce good dispersion and high oxidation stability. The powder produced by interesterification does not differ significantly from commercial products.

Soybean oil can also be used to make trans-free margarine which has good health effects. Applications for margarine are usually mixed with other oil sources such as palm kernel oil and palm stearin either through the blending or interesterification [39], [40]. Li et al. [28] succeeded in producing low trans margarine from soybean oil and fully hydrogenated palm oil (FHPO) blends, then compared with beef tallow (BT). BT is often used as a raw material for the production of margarine due to its preferred plasticity and taste characteristics. Nevertheless, BT margarine produces a rough crystalline texture that gives a gritty feel [41]. In addition, high cholesterol and saturated fatty acids in BT can be a health risk [42], [43]. The optimum ratio of SO and FHPO to produce margarine was 4:3. Unsaturated fatty acids at interesterified oil (IO) were greater than BT. Trans fatty acids from IO $(0.67 \%)$ were much smaller than BT $(4.15 \%)$. IO had a TAG arrangement that resembles BT, where TAGs were more diverse such as palmitate-palmitate-stearate and palmitate-stearate-stearate, so as to increase the $\beta^{\prime}$ crystals which are preferred for margarine. IO had a melting point which was preferred for the food industry, which was 29.1-48.8 ${ }^{\circ} \mathrm{C}$ when compared to BT $\left(34.5-56.1{ }^{\circ} \mathrm{C}\right)$.

IO had a slow crystallization rate so that its stability characteristics are suitable for margarine. Solid fat content in margarine greatly affects the appearance, mouthfeel, spreadability, packaging, and organoleptic properties. The SFC value of IO was quite high at temperatures less than 10 ${ }^{\circ} \mathrm{C}$ and reached 0 at $45{ }^{\circ} \mathrm{C}$. Therefore, IO is suitable as a substitute for BT as a raw material for the production of margarine and shortening because it has a lower melting point [44].

Crystal structure affects the texture and organoleptic margarine. Large crystals can give the impression of sand [45]. IO has crystals such as small aggregate plates that are evenly distributed, whereas BT has crystalline globules that are dense and concentrated. Interesterification improves the texture and quality of organoleptic margarine because it has a smaller $\beta^{\prime}$-form. IO also has a higher spreadability than BT and SO-FHPO blend. In another study, Pande and Akoh [29] succeeded in producing trans-free margarine through interesterification of high stearate soybean oil with palm stearin. The margarine fat obtained has $\beta^{\prime}$ polymorph and physicochemical properties suitable for margarine.

\subsection{Recombined Butter}

Butterfat has a specific taste that consumers like and contains several fat-soluble vitamins. However, butter has the 
disadvantage of poor spreadability and high saturated fatty acids. Therefore, it is necessary to develop a new butter product in the form of recombined butter which has a good melting profile and contains lower saturated fatty acids [46].

Nunes et al. [30] investigated the characteristics of milk fat-soybean oil blend (MF-SBO), which were interesterified using immobilized 1,3- specific lipase from Aspergillusniger. TAG of milk fat contains medium-chain and short-chain fatty acids crystallized into $\beta^{\prime}$-form. TAG of soybean oil contains long-chain fatty acids and medium-chain crystallized in the $\beta$-form [47]. The triacylglycerol (TAG) arrangement in the MF:SBO blend at a ratio of 25:75 results in a decrease in TAG C54 and an increase in TAG C40-C52. Whereas the mixture of MF: SBO at a ratio of 67:33 results in an increase in C46-C52 and a decrease in TAG C54 and C40-C44. The blend at a ratio of 67:33 results in the highest interesterification yield compared to other blends.

The interesterification product (EIE) from the MF-SBO blend of 67:33 has a higher level of spreadability than pure butterfat and milk fat. The blend of 67:33 has a lower consistency and hardness value than pure butter and milk fat. The enzymatic interesterification product MF: SBO at a ratio of 67:33 is the best EIE that has better spreadability than pure butter and milk fat. In another study, [31] mixed FHSBO oil with anhydrous milk fat. The results showed that FHSBO has compatibility with milk fat. In addition, FHSBO increased the thermal resistance and improved the polymorphic properties of blends

\subsection{MonoacylglycerolandDiacylglycerol}

Monoacylglycerol (MAG) and diacylglycerol (DAG) are minor components in various oils with a proportion of 1-16\%. MAG contains one fatty acid that is esterified to the glycerol backbone, whereas DAG contains two fatty acids that are esterified to the glycerol backbone with possibly two types of DAGs (1,3-DAG and 1,2-DAG) [48]. Generally, MAG and DAG are used as additives in food production systems, or can also be an emulsifier for food, cosmetics, and medicine [49]-[51]. DAG-rich oils have been widely studied as an alternative to TAG-based oils to inhibit fat accumulation and reduce the level of postprandial TAG in the blood [52]. DAG-rich oils have higher melting points than TAG-based oils, even though their fatty acid composition is almost the same [53]. Therefore, DAG rich oils have been used in many fatty food formulations in Japan and America for the past ten years [54].

Zhang et al. (Zhang et al., 2018) produced DAG-rich soybean oil through enzymatic hydrolysis, then applied to mice. The results showed that DAG-rich soybean oil could prevent obesity and reduce serum triglycerides in mice. In another study, Chen et al. [32] succeeded in producing soybean oil rich in diacylglycerol through enzymatic interesterification. The product is then purified using molecular distillation (MD). Purification produces MD residuals (diacylglycerol-enriched oils) and MD Distillate (by-product). Iodine number analysis indicated that $\mathrm{MD}$ residuals (diacylglycerol-enriched oils) have high unsaturated fatty acids. The DAG content in MD residuals has increased by $22.6 \%$. Monoacylglycerol (MAG) is found in many MD distillates with a MAG purity of $82.9 \%$. Based on these results, the method used by Chen et al. [32] produced DAG-enriched oil as well as MAG, which have low iodine numbers. Solid fat content in the MD residual has the potential to be used as liquid margarine since it has a $6 \%$ SFC at $10^{\circ} \mathrm{C}$ and almost none at $35^{\circ} \mathrm{C}$.

\section{CONCLUSION}

Soybean oil is rich in unsaturated fatty acids such as linoleic and oleic acids. It has been used in various food industries both naturally and through lipid modification. Recent soybean oil applications include the production of free of trans-free margarine and creamer, recombined butter, oleogels/organogels, and mono- and diacylglycerols. The use of soybean oil has been proven to fix up the physical, chemical, and nutritional properties of margarine, recombined butter, and various fat/oil-based food products.

\section{ACKNOWLEDGEMENT}

The authors would like to thank the Rector of UniversitasPadjadjaran and the Ministry of Education and Culture of the Republic of Indonesia for the support provided.

\section{REFERENCES}

1. T. Wang, Soybean Oil, in Vegetable Oils in Food Technology: : Composition, Properties and Uses, 2nd ed., F. D. Gunstone, Ed. Oxford, UK: Wiley-Blackwell, 2011, pp. 59-105.

2. E. Subroto and M. A. H. Qonit, Modification of soy protein for the production of bioactive peptides and their utilization, Int. J. Sci. Technol. Res., vol. 9, no. 2, pp. 3121-3127, 2020.

3. F. Anwar, G. M. Kamal, F. Nadeem, and G. Shabir, Variations of quality characteristics among oils of different soybean varieties, J. King Saud Univ. - Sci., vol. 28, no. 4, pp. 332-338, 2016. https://doi.org/10.1016/j.jksus.2015.10.001

4. D. R. Johnson and E. A. Decker, The Role of Oxygen in Lipid Oxidation Reactions: A Review, Annu. Rev. Food Sci. Technol., vol. 6, pp. 171-190, 2015. https://doi.org/10.1146/annurev-food-022814-015532

5. A. P. B. Ribeiro, R. Grimaldi, L. A. Gioielli, and L. A. G. Gonçalves, Zero trans fats from soybean oil and fully hydrogenated soybean oil: Physico-chemical properties and food applications, Food Res. Int., vol. 42, no. 3, pp. 401-410, 2009. https://doi.org/10.1016/j.foodres.2009.01.012

6. D. D. Asbridge, Soybeans vs. Other Vegetable Oils as a Source of Edible Oil Products, in Practical Handbook of Soybean Processing and Utilization, AOCS Press, Champaign, IL, 1995.

7. S. N. Sahasrabudhe, V. Rodriguez-Martinez, M. O'Meara, and B. E. Farkas, Density, viscosity, and 
surface tension of five vegetable oils at elevated temperatures: Measurement and modeling, Int. J. Food Prop., vol. 20, no. 2, pp. 1965-1981, 2017. https://doi.org/10.1080/10942912.2017.1360905

8. A. Thomas, Fats and Fatty Oils, in Ullmann's Encyclopedia of Industrial Chemistry, Weinheim, Germany: Wiley-VCH Verlag GmbH \& Co. KGaA, 2000.

9. F. Shahidi, Bailey's Industrial Oil and Fat Products, Volumes 1-6 (6th Edition), Bailey's Industrial Oil and Fat Products. pp. 303-332, 2005.

10. J. C. O. Santos, M. G. O. Santos, J. P. Dantas, M. M. Conceicao, P. F. Athaide-Filho, and A. G. Souza, Comparative study of specific heat capacities of some vegetable oils obtained by DSC and microwave oven, J. Therm. Anal. Calorim., vol. 79, no. 2, pp. 283-287, 2005. https://doi.org/10.1007/s10973-005-0050-x

11. R. T. Nassu and L. A. G. Gonçalves, Determination of melting point of vegetable oils and fats by differential scanning calorimetry (DSC) technique, Grasas y Aceites, vol. 50, no. 1, pp. 16-22, 1999. https://doi.org/10.3989/gya.1999.v50.i1.630

12. I. Karabulut, S. Turan, and G. Ergin, Effects of chemical interesterification on solid fat content and slip melting point of fat/oil blends, Eur. Food Res. Technol., vol. 218, no. 3, pp. 224-229, 2004. https://doi.org/10.1007/s00217-003-0847-4

13. A. T. Oladiji, K. L. Shoremekun, and M. T. Yakubu, Physicochemical properties of the oil from the fruit of blighiasapida and toxicological evaluation of the oil-based diet in wistar rats, J. Med. Food, vol. 12, no. 5, pp. 1127-1135, Oct. 2009. https://doi.org/10.1089/jmf.2008.0219

14. I. N. Hayati, Y. B. C. Man, C. P. Tan, and I. N. Aini, Physicochemical characteristics of soybean oil, palm kernel olein, and their binary blends, Int. J. Food Sci. Technol., vol. 44, no. 1, pp. 152-161, 2009.https://doi.org/10.1111/j.1365-2621.2007.01700.x

15. J. Orsavova, L. Misurcova, J. V. Ambrozova, and R. Vicha, Fatty Acids Composition of Vegetable Oils and Its Contribution to Dietary Energy Intake and Dependence of Cardiovascular Mortality on Dietary Intake of Fatty Acids, Int. J. Mol. Sci., vol. 16, pp. 12871-12890,

2015.https://doi.org/10.3390/ijms160612871

16. E. R. Machado, M. Del Carmen DobarganesGarcía, and S. De Mello Pereira Abrantes, Palm and soybean oils alterations in the discontinued frying of potatoes, Cienc. eTecnol. Aliment., vol. 28, no. 4, pp. 786-792, 2008.https://doi.org/10.1590/S0101-2061200800040000 4

17. M. D. Juárez, C. C. Osawa, M. E. Acuña, N. Sammán, and L. A. G. Gonçalves, Degradation in soybean oil, sunflower oil and partially hydrogenated fats after food frying, monitored by conventional and unconventional methods, Food Control, vol. 22, no. 12, pp. 1920-1927, 2011.

https://doi.org/10.1016/j.foodcont.2011.05.004

18. I. Karabulut, M. Kayahan, and S. Yaprak, Determination of changes in some physical and chemical properties of soybean oil during hydrogenation, Food Chem., vol. 81, no. 3, pp. 453-456, 2003.https://doi.org/10.1016/S0308-8146(02)00397-7

19. J. N. Rodrigues and L. A. Gioielli, Chemical interesterification of milkfat and milkfat-corn oil blends, Food Res. Int., vol. 36, no. 2, pp. 149-159, Jan. 2003.https://doi.org/10.1016/S0963-9969(02)00130-8

20. B. H. Kim and C. C. Akoh, Recent Research Trends on the Enzymatic Synthesis of Structured Lipids, J. Food Sci., vol. 80, no. 8, pp. 1713-1724, 2015. https://doi.org/10.1111/1750-3841.12953

21. C. C. Akoh and D. B. Min, Food lipids: Chemistry, nutrition, and biotechnology. Boca Raton, Florida: CRC Press, 2008.

22. L. Phan, H. Brown, J. White, A. Hodgson, and P. G. Jessop, Soybean oil extraction and separation using switchable or expanded solvents, Green Chem., vol. 11, no. 1, pp. 53-59, 2009.https://doi.org/10.1039/b810423a

23. J. Lim, S. Jeong, I. K. Oh, and S. Lee, Evaluation of soybean oil-carnauba wax oleogels as an alternative to high saturated fat frying media for instant fried noodles, LWT - Food Sci. Technol., vol. 84, pp. 788-794, 2017.https://doi.org/10.1016/j.lwt.2017.06.054

24. H. Si, L. Z. Cheong, J. Huang, and X. Wang, Physical Properties of Soybean Oleogels and Oil Migration Evaluation in Model Praline System, J. Am. Oil Chem. Soc., vol. 93, pp. 1075-1084, 2016. https://doi.org/10.1007/s11746-016-2846-1

25. R. Tarté, J. S. Paulus, N. C. Acevedo, K. J. Prusa, and S.-L. Lee, High-oleic and conventional soybean oil oleogels structured with rice bran wax as alternatives to pork fat in mechanically separated chicken-based bologna sausage, LWT - Food Sci. Technol., p. 109659, 2020.https://doi.org/10.1016/j.lwt.2020.109659

26. K. R. R. de Godoi, R. C. Basso, C. C. Ming, A. Á. da Silva, L. P. Cardoso, and A. P. B. Ribeiro, Crystallization, microstructure and polymorphic properties of soybean oil organogels in a hybrid structuring system, Food Res. Int., vol. 137, p. 109460, 2020.https://doi.org/10.1016/j.foodres.2020.109460

27. B. Wang and J. Liu, Trans-free nondairy creamer prepared from enzymatic interesterification of soybean oil and fully hydrogenated soybean oil, J. Food Process Eng., vol. 37, no. 4, pp. 339-348, 2014.https://doi.org/10.1111/jfpe.12090

28. Y. Li, J. Zhao, X. Xie, Z. Zhang, N. Zhang, and Y. Wang, A low trans margarine fat analog to beef tallow for healthier formulations: Optimization of enzymatic interesterification using soybean oil and fully hydrogenated palm oil, Food Chem., vol. 255, pp. 405-413,

2018.https://doi.org/10.1016/j.foodchem.2018.02.086

29. G. Pande and C. C. Akoh, Enzymatic synthesis of trans-free structured margarine fat analogs with high stearate soybean oil and palm stearin and their characterization, LWT - Food Sci. Technol., vol. 50, no. 1, pp. 232-239, 2013. https://doi.org/https://doi.org/10.1016/j.lwt.2012.05.027

30. G. F. M. Nunes, A. V. de Paula, H. F. de Castro, and J. C. dos Santos, Compositional and textural properties of 
milkfat-soybean oil blends following enzymatic interesterification, Food Chem., vol. 125, no. 1, pp. 133-138,

2011.https://doi.org/10.1016/j.foodchem.2010.08.049

31. M. I. L. Neves, M. de S. Queirós, R. L. S. Viriato, A. P. B. Ribeiro, and M. L. Gigante, Physicochemical characteristics of anhydrous milk fat mixed with fully hydrogenated soybean oil, Food Res. Int., vol. 132, p. 109038, 2020.

https://doi.org/https://doi.org/10.1016/j.foodres.2020.10 9038

32. Q. Chen, Y. Li, J. Fu, X. Ma, Y. Teng, and Y. Wang, Production of diacylglycerol-enriched oils by enzymatic interesterification and molecular distillation using soybean oil and distilled saturated monoacylglycerol, Eur. J. Lipid Sci. Technol., vol. 119, no. 6, Jun. 2017.https://doi.org/10.1002/ejlt.201600332

33. M. Zhang, B. Shi, C. Li, and Y. Cheng, Diacylglycerol-enriched Oil from Hydrolysis of Soybean Oil with RhizopusOryzae Lipase against High-fat Diet-induced Obesity in Mice, Grain Oil Sci. Technol., vol. 1, no. 1, pp. 53-58, 2018 https://doi.org/10.3724/SP.J.1447.GOST.2018.18026

34. J. F. Toro-Vazquez, J. A. Morales-Rueda, E. Dibildox-Alvarado, M. Charó-Alonso, M. Alonzo-Macias, and M. M. González-Chávez, Thermal and textural properties of organogels developed by candelilla wax in safflower oil, J. Am. Oil Chem. Soc., vol. 84, no. 11, pp. 989-1000, 2007.https://doi.org/10.1007/s11746-007-1139-0

35. M. C. Chiu, L. A. Gioielli, and R. Grimaldi, Lipídiosestruturadosobtidos a partir da mistura de gordura de frango, suaestearina e triacilgliceróis de cadeiamédia. I- composiçãoemácidosgraxos e emtriacilgliceróis, Quim. Nova, vol. 31, no. 2, pp. 232-237, 2008.

https://doi.org/10.1590/S0100-40422008000200008

36. E. Fattahi-Far, M. A. Sahari, and M. Barzegar, Interesterification of tea seed oil and its application in margarine production, J. Am. Oil Chem. Soc., vol. 83, no. 10 , pp. 841-845, Oct. 2006.

https://doi.org/10.1007/s11746-006-5035-9

37. R. Indiarto, B. Nurhadi, Tensiska, E. Subroto, and Y. J. Istiqamah, Effect of liquid smoke on microbiological and physico-chemical properties of beef meatballs during storage, Food Res., vol. 4, no. April, pp. 522-531, 2020.https://doi.org/10.26656/fr.2017.4(2).341

38. E. Subroto and F. Hayati, Chemical and Biotechnological Methods for the Production of Xylitol : A Review, Int. J. Emerg. Trends Eng. Res., vol. 8, no. 6, pp. 2508-2512, 2020. https://doi.org/10.30534/ijeter/2020/49862020

39. E. Subroto and R. L. Nurannisa, The Recent Application Of Palm Stearin In Food Industry : A Review, Int. J. Sci. Technol. Res., vol. 9, no. 2, pp. 2593-2597, 2020.

40. S. Hazirah, M. F. Norizzah, and O. Zaliha, Effects of chemical interesterification on the physicochemical properties of palm stearin, palm kernel oil and soybean oil blends, Malaysian J. Anal. Sci., vol. 16, no. 3, pp. 297-308, 2012.

41. Z. Meng, Y. Liu, L. Shan, Q. Jin, F. Wang, and X. Wang, Specialty Fats from Beef Tallow and Canola Oil: Establishment of Reaction Conditions, Characterization of Products, and Evaluation of Crystal Stability, Food Biophys., vol. 6, no. 1, pp. 115-126,

2011.https://doi.org/10.1007/s11483-010-9186-8

42. A. E. A. Altoum, A. M. Babker, M. Ismail, and V. Lyashenko, A Study of Correlation Ratios for Lowand High-Density Lipoprotein in Comparison with Antioxidant Vitamins A, E, C at Different Levels of Glycosylated Hemoglobin among Type 2 Diabetes Patients, Int. J. Emerg. Trends Eng. Res., vol. 8, no. 3, pp. 638-644, Mar. 2020.

https://doi.org/10.30534/ijeter/2020/05832020

43. J. H. Y. Wu, R. Micha, and D. Mozaffarian, Dietary fats and cardiometabolic disease: mechanisms and effects on risk factors and outcomes, Nat. Rev. Cardiol., vol. 16, no. 10, pp. 581-601, 2019. https://doi.org/10.1038/s41569-019-0206-1

44. L. Ahmadi and A. G. Marangoni, Functionality and physical properties of interesterified high oleic shortening structured with stearic acid, Food Chem., vol. 117, no. 4, pp. 668-673, 2009.

https://doi.org/10.1016/j.foodchem.2009.04.072

45. D. Li, P. Adhikari, J.-A. Shin, J.-H. Lee, Y.-J. Kim, X.-M. Zhu, J.-N. Hu, J. Jin, C.C. Akoh, K.-T. Lee,Lipase-catalyzed interesterification of high oleic sunflower oil and fully hydrogenated soybean oil comparison of batch and continuous reactor for production of zero trans shortening fats, LWT - Food Sci. Technol., vol. 43, no. 3, pp. 458-464, 2010. https://doi.org/10.1016/j.lwt.2009.09.013

46. E. Subroto, T. Tensiska, R. Indiarto, H. Marta, and A. S. Wulan, Physicochemical and sensorial properties of recombined butter produced from milk fat and fish oil blend, Biosci. Res., vol. 15, no. 4, pp. 3733-3740, 2018.

47. B. S. Ghotra, S. D. Dyal, and S. S. Narine, Lipid shortenings: A review, Food Res. Int., vol. 35, no. 10, pp. 1015-1048, 2002. https://doi.org/10.1016/S0963-9969(02)00163-1

48. J. A. Laszlo, D. L. Compton, and K. E. Vermillion, Acyl migration kinetics of vegetable oil 1,2-diacylglycerols, J. Am. Oil Chem. Soc., vol. 85, no. 4, pp. 307-312, 2008.https://doi.org/10.1007/s11746-008-1202-5

49. E. Subroto, M. F. Wisamputri, Supriyanto, T. Utami, and C. Hidayat, Enzymatic and chemical synthesis of high mono- and diacylglycerol from palm stearin and olein blend at different type of reactor stirrers, J. Saudi Soc. Agric. Sci., vol. 19, no. 1, pp. 31-36, 2020. https://doi.org/10.1016/j.jssas.2018.05.003

50. E. Subroto, Monoacylglycerols and diacylglycerols for fat-based food products: a review, Food Res., vol. 4, no. 4, pp. 932-943, 2020. https://doi.org/10.26656/fr.2017.4(4).398

51. N. Liu, Y. Wang, Q. Zhao, Q. Zhang, and M. Zhao, Fast synthesis of 1,3-DAG by Lecitase ${ }^{\circledR}$ Ultra-catalyzed 
esterification in solvent-free system, Eur. J. Lipid Sci. Technol., vol. 113, no. 8, pp. 973-979, 2011 https://doi.org/10.1002/ejlt.201000507

52. R. Baeza-Jiménez, K. Miranda, H. S. García, and C. Otero, Lipase-catalyzed glycerolysis of fish oil to obtain diacylglycerols, Grasas y Aceites, vol. 64, no. 3, pp. 237-242, Jun. 2013.

https://doi.org/10.3989/gya.084412

53. S. K. Lo, C. P. Tan, K. Long, M. S. A. Yusoff, and O. M. Lai, Diacylglycerol oil-properties, processes and products: A review, Food Bioprocess Technol., vol. 1, no. 3, pp. 223-233, 2008. https://doi.org/10.1007/s11947-007-0049-3

54. T. Yang, H. Zhang, H. Mu, A. J. Sinclair, and X. Xu, Diacylglycerols from butterfat: Production by glycerolysis and short-path distillation and analysis of physical properties, J. Am. Oil Chem. Soc., vol. 81, no. 10, pp. 979-987, 2004.

https://doi.org/10.1007/s11746-004-1010-8 